\title{
Posesa, mística, obsesa: el caso de posesión diabólica de Jeanne Féry, sœur noir del convento de Mons a fines del siglo $\mathrm{XVI} *$
}

Possessed, mystic, obssessed: the case of diabolic possession of Jeanne Féry, SaEUR noir from the Mons convent at the end of the $\mathrm{XVI}{ }^{\mathrm{TH}}$ century .

\section{(4) Carlos Manuel García}

Universidad de Buenos Aires, Argentina

Fecha de Recepción: Noviembre 2018. Fecha de Aceptación: Noviembre 2018.

\section{Resumen}

La posesión diabólica fue una compleja experiencia cultural muy común en la sociedad tempranomoderna. Este estudio está orientado a presentar una primera aproximación al caso de posesión diabólica (mezclada con elementos característicos del misticismo y la obsesión) que la sœur noir Jeanne Féry sufrió durante los años 1584 y 1585 en Mons, frontera de los Países Bajos Españoles, haciendo corresponder esta invasión espiritual maligna con los violentos problemas confesionales que católicos y calvinistas mantenían en la Europa del siglo XVI.

\begin{abstract}
The diabolical possession was a complex cultural experience very common in the early modern society. This study is oriented to exhibit a first approximation to the case of diabolic possession (mixed with characteristic elements of mysticism and obsession) that the saur noir Jeanne Fey suffered during the years 1584 and 1585 in Mons, border of the Spanish Netherlands, corresponding this evil spiritual invasion with the violent confessional problems that Catholics and Calvinists maintained in sixteenth-century Europe.
\end{abstract}

\section{Introducción}

Durante la segunda mitad del siglo XVI podemos observar un recrudecimiento de los problemas interconfesionales en el territorio francés (Pearl, 1999: 1-6). Las agonales inquinas entre católicos y protestantes se agravaron de manera superlativa, dando origen a un conjunto de episodios violentos y matanzas, que se extendieron hacia otras latitudes (Oberman, 1994: 217-220).

* Artículo entregado en el marco de las VII Jornadas de Reflexión Histórica: Las formas del conflicto religioso y de la violencia simbólica en el espacio cultural europeo (siglos XIV a XVIII): actores, dispositivos, escenarios, estrategias", organizadas por el Instituto de Historia Antigua y Medieval, (Facultad de Filosofía y Letras, Universidad de Buenos Aires), el 5 de diciembre de 2018.
Palabras clave

Posesión misticismo problemas confesionales Calvinismo Catolicismo eucaristía

\section{Keywords}

Possession Mysticism Confessional problems

Calvinism Catholicism Eucharist 
Ese es el contexto político y social en el que se desarrolla en Mons (Países Bajos Españoles) el caso de posesión diabólica de Jeanne Féry, monja del convento de las Sceur Noires de la provincia de Hainaut. Entre abril de 1584 y enero de 1586, la monja experimenta una tremebunda consecución de acontecimientos que podemos calificarlos como posesión demoníaca, obsesión diabólica y visiones místicas. Aunque la fuente que nos llega de dichas vicisitudes de la religiosa haya titulado el caso como una historia de posesión, la lectura pormenorizada del texto amplía el rango empírico de dichos sucesos.

Este trabajo tiene la preliminar intención de hacer un resumen cronológico de los acontecimientos del caso. A continuación, analizaremos las experiencias de posesión, obsesión y misticismo que el registro documental nos permite reconstruir. La finalidad de este excurso es demostrar que lejos de ser meramente un caso de posesión diabólica convencional, la "posesión de Jeanne Féry" encierra dentro de sí misma elementos mucho más complejos y matizados, que son necesarios de analizar en el contexto de época en el que tales sucesos se produjeron. Este caso está inmediatamente relacionado con problemas culturales propios de la temprana modernidad, como fueron las diferencias teológicas entre las confesiones católicas y protestantes, las disputas sobre la presencia real o no de Cristo en el sacramento de la hostia, la demonología, la caza de brujas y el proceso de aumento de control de los poderes eclesiásticos al calor de la institucionalización del discernimiento de espíritus, entre otros.

\section{La posesión de Jeanne Féry: una cronología del caso}

El 10 de abril de 1584, François Buisseret, archidiácono de la diócesis de Cambrai, presentó a la posesa Jeanne Féry al arzobispo Louis de Berlaymont. Este la bendijo, debido a su estado de debilidad, producto de la posesión diabólica que sufría. Aun así, la religiosa empeoró. Días después fue obligada a asistir a misa y, luego de la misma, a comenzar con los exorcismos. Fue allí donde los malignos dijeron por primera vez su nombre. Namón fue el primero de ellos en manifestarse y fue vencido por la ayuda de Santa María Magdalena, quien de aquí en adelante sería la férrea defensora de la joven monja. Sin embargo, el vencer a este diablo no mejoró el cuadro de situación: todo lo contrario, empeoró las características del mismo. No sólo sufrió los cimbronazos corporales y las llamativas características de un caso de expulsión de demonios, sino que además la posesa comenzó a rechazar aspectos fundamentales del credo y a dudar o debatir los artículos de la fe. Esto llevó a que el arzobispo se sintiera alarmado de la situación y formara una junta de especialistas que acompañara el caso. Dicha junta estaba formada por el antes mencionado François Buisseret (quien además de oficiar de archidiácono, fue el redactor del documento final donde se contó la penuria de la religiosa), Nicolas Goubille (canon de Notre-Dame de Cambrai), Jean Mainsent (canon de Saint-Germain de Mons y quien más tarde oficiaría de "padre" sustituto de la posesa), Jacques Joly (cura del vecino convento de Béguinage de Cantimpret) y Michelle Bavay (confesor de las Sour Noires). Dicha comitiva que tenía la misión de hacer que Jeanne se retractara, devolviéndola así a la fe católica, estaba bajo la dirección espiritual e institucional del mismísimo Louis de Berlaymont.

Durante ese mes de abril y el siguiente, Jeanne peregrinó a los santuarios de Mons y zonas aledañas circundantes del sur de los actuales Países Bajos. Allí trabó contacto con distintas reliquias. Estos objetos de veneración contribuyeron a la mejora efectiva de la situación de la religiosa. Sin embargo, pronto su situación empeoró. Durante el transcurso del mes de junio, se pudieron observar las violentas manifestaciones de su estado. Comenzó a presentar síntomas de anorexia y problemas para ingerir alimentos, llevó a cabo varios intentos de suicidio y se lastimó con frenesí su cuerpo, intentó arrojarse de una ventana, trató de ahogarse en un río, etc. Las superioras del 
convento intentaban ayudarla para que dejara de hacerse daño, atándola y manteniéndola encerrada, pero la joven Jeanne lograba siempre escapar. Su situación anímica también transmutó en múltiples fases que iban desde la ira al llanto, del odio a la depresión. Debido a ello, se le asignó como guardiana y acompañante a la monja y futura superiora del convento, Bárbara Dervilliers. Esta última, veló la salud física y psicológica de la joven religiosa. Durante ese periodo recibió visiones de Santa María Magdalena, quien la obligó a confesar su secreto: tenía dieciocho pactos con los demonios y, además había acumulado hostias consagradas en su cuerpo a pedido de ellos. Casi hasta el fin del año continuaron realizándole exorcismos a la religiosa. Estos ritos se dieron en su totalidad a puertas cerradas, en el convento, y allí quedo demostrada la potencia espiritual del sacramento de la hostia y la confirmación de que la presencia real de Cristo era una verdad insoslayable. Durante los exorcismos, se quemaron los pactos de sangre que Jeanne había firmado con los demonios y además ésta consumió las hostias consagradas que había profanado; también en el mes de mayo tuvo una visión gloriosa de Cristo como Rey en el cielo que le confirmaba místicamente la comprobación de la verdad de la doctrina cristiana. Así, en el mes de septiembre, con el regreso de Luis de Berlaymont a la diócesis de Cambrai, sólo quedaban dos demonios: Garga que se va rápido y Cornau quien es el primer demonio que la había poseído y el que había oficiado como "padre" de la religiosa, luego del abandono de su progenitor cuando tenía cuatro años. Cornau le había enseñado todo lo que Jeanne sabía, por lo que la expulsión del mismo la devolvería a la infancia. Antes de la expulsión de este diablo-padre de la joven, Jean Mainsent se ofrece a suplantarlo como figura paterna y Louis de Berlaymont va a pasar a ocupar el rol de abuelo. Habiendo logrado esta homologación de roles de progenitores, Cornau es expulsado y tal como se había dicho, la religiosa volvió a su estado de niñez. Santa María Magdalena apareció y dejó en la boca de Jeanne una nota en donde dice que el arzobispo debe custodiar y alimentar por un año a la joven monja, además de alojarla e instruirla. Así, de manera progresiva, ésta fue recuperando el juicio.

Habiendo sido expulsado el último y más potente de los demonios, el cuadro de situación de la monja Féry cambia radicalmente: deja de ser una posesa por diablos para convertirse en una obsesa. Durante un año, más o menos, va a sufrir los embates de los demonios que la van a acosar de manera sistemática. Esto fue producto de la propia conducta de la religiosa, debido a que la misma no era completamente inocente por haber mantenido tratos con los demonios y dudar de algunos de los dogmas elementales de la fe, como el milagro eucarístico o la crucifixión de Cristo. Además, su situación empeoraba al momento en el cual el arzobispo, con la finalidad de controlar las habladurías, dejaba a la monja en el convento o no se hacia cargo diariamente de ella. Cada vez que este deseaba dejar de darle hospedaje y reingresarla al convento, los demonios se ponían muy violentos. Recién durante el mes de agosto de 1585, la santa de Magdala le permitió la reincorporación al claustro conventual. Pero esto no marcó el fin de sus penurias. En una visión, nuevamente la santa le anunció una gran batalla entre las huestes del demonio y del bien. Postrada, y rodeada por Mainsent y de Berlaymont, la joven monja se preparó para este combate definitivo. A la derecha de la obsesa se posicionó Santa María Magdalena, a la izquierda los demonios que la acechaban. Durante el frenético combate que sucedió el 12 de noviembre de 1585, Jeanne invocó la salvación por la cruz de Cristo y tras una inmensa agonía, se proclamó la victoria de las fuerzas celestiales y el fin de la obsesión. La joven estaba completamente liberada. Desde el 13 de noviembre hasta el 24 del mismo mes, a pedido de la santa defensora de la ex posesa, la monja contó la historia de sus avatares al convento de las Sceur Noires primero y a toda la comunidad de Mons, después. Pero las deformaciones de lo ocurrido llevaron al arzobispo Louis de Berlaymont (y con la aprobación y visto bueno de Santa María Magdalena) a instar a la joven religiosa a poner por escrito su historia. Por esta razón, durante los cuatro días que acontecieron entre el 25 y el 29 de noviembre de 1585, Jeanne Féry reconstruyó por 
escrito los brutales sucesos que le tocaron vivir. El día de reyes del subsiguiente año, la monja vivió un episodio de éxtasis supremo, donde se le confirmó la liberación total de su condición de dolencia. De allí en más, su vida como religiosa continuó sin sobresaltos ni alteraciones. Treintaicuatro años después, la monja Jeanne Féry, murió en el convento de las Sceur Noires de Mons (Bourneville, 1886).

\section{Posesa, mística y obsesa: una lectura de la Histoire admirable et véritable en clave histórica}

A continuación, luego de haber presentado de manera más o menos esquemática los bizarros acontecimientos que sufrió Jeanne Féry en su posesión, rastrearemos a manera de demostración efectiva, algunas de las experiencias que confirman nuestra hipótesis; a saber, que más allá de un clásico caso de posesión demoníaca, el de la religiosa es fue un evento de una compleja multiplicidad de aristas, de las cuales quedó claro que más que una intromisión de fuerzas malignas, lo que en verdad sufrió la monja fue una invasión espiritual de tipo preternatural y sobrenatural, entre fuerzas del bien y del mal que se disputaron su cuerpo como campo de batalla entre los justos seguidores de Dios y los adláteres de Satanás. En esta feroz disputa espiritual quedaron en evidencia algunos de los problemas que las confesiones cristianas rivales tenían en su época. Esto se puede observar en un acontecimiento particular, que nos sirve para ilustrar los agudos conflictos que hugonotes y católicos mantenían en el terreno teológico.

Durante su autobiografía, la ex posesa contó que vio una procesión a favor de la santa hostia, en la que un gran numero de personas proclamaban la primacía de la fe católica y la presencia real de Cristo en el sacramento eucarístico. Así relató Jeanne:

Voyant quelque autre fois la procession passée par devant le logis là où je me tenais, et étant appelée pour adorer le Saint-Sacrement, toutefois n'ensuivant point le conseil de ma compagnie qui m'appelait pour le regarder d'en-bas, je montais en-haut afin d'avoir moyen de le blasphémer à mon aise. Voyant le peuple avec lumière, avec toute révérence, je mémerveillais fort que tant de gens et de si grande qualité prenaient la peine de suivre la chose, laquelle m'était si abominable. Car j'eusse été contente d'endurer plutôt tous les tourments du monde, que d'adorer une seule fois cette sainte hostie. Et la voyant passer, je commençai à rire, et me moquer, injurier, blasphémer. Et disais en moi-même que celui que les chrétiens adorent se laissait porter par des hommes, et si honteusement que toujours en forme d'un homme tout nu et étendu en une croix, et lui attribuais toute vilenie et méchanceté. Et me disaient ces méchants diables [que] l'occasion que Dieu était ainsi mis en une croix tout nue était pour attirer le monde à toute méchanceté et paillardise avec lui. Ce que toutefois à cette heure, je le confesse et l'adore, et le reconnais avec tout honneur et révérence, croyant fermement que c'est mon Dieu et abjurant et détestant ces méchants diables. Étant descendue en-bas, je demandai à un autre personnage, lequel était auprès de moi, pourquoi cétait qu'il était descendu devant que le Sacrement fût passé. Me répondit qu'il n'avait point la folie des chrétiens et qu'il adorait le Dieu d'en-haut mais non point le dieu qu'on portait en ses mains et qu'il nétait possible que Dieu descendait du ciel, et qu'il serait encore en ce monde ici, et qu'il se laisserait porter des hommes, que cétait chose impossible. Et disputant longtemps à deux, nous accordâmes fort bien par ensemble, et que la forme de pain ne pouvait devenir Dieu à la simple parole des hommes, détestant et abhorrant les prêtres qui usaient de tels sacrifices et qui trompaient ainsi les simples gens (ibid, 90-91). 
Queda clara, en este breve extracto de la fuente, la relación que el caso de posesión de Jeanne Féry tiene con la realidad histórica en la que vivió. Su sociedad estaba profundamente dividida por el cisma religioso entre distintas fes; y, sin duda, el desarrollo de los brutales acontecimientos que transitó, dejó ver eso. En este caso, frente a una procesión de católicos que revindicaban el poder del sacramento de la eucaristía, cuya gracia era ni más ni menos que la presencia real del propio Cristo en la ceremonia religiosa de la misa, la joven monja fue incitada por los demonios a atacar y burlarse de la hostia (Ferber, 2004: 15-21). En una ciudad profundamente católica como era Mons, frontera confesional al mismo tiempo con los iconoclastas calvinistas del norte, los demonios de Jeanne la llevaron a actuar como una protestante y a homologar su pensamiento teológico el cual afirmaba la imposibilidad de la transubstanciación. Este doble aspecto de ataque a la hostia y la completa seguridad de que era un error el creer en la presencia real, justamente estaba confirmando la veracidad de la fe y el dogma católico. Los demonios tomaban represalias contra la molesta presencia de la divinidad en la eucaristía, al mismo tiempo que intentaron confundir a la religiosa y a algunos miembros de la comunidad con la idea de que la hostia no era el cuerpo de cristo in stricto sensu.

El diálogo que mantuvo con un hombre que pasaba por allí, también fue muestra de que las propias comunidades se veían divididas hacia adentro por las querellas teológicas. Este sujeto le comentó a la joven Jeanne que era una locura que los católicos creyeran verdaderamente que un pan se convirtiera en Dios. Tanto la religiosa confundida por los demonios que acrecentaban sus dudas sobre el milagro eucarístico, como el sujeto pasajero que criticaba a los católicos y sus practicas religiosas estaban tomando partido por la teología protestante. De hecho, fue esa presunta falsedad en el credo lo que llevó a Jeanne a burlarse no sólo del sacramento de la hostia, sino también de la imagen de Cristo en un crucifijo y de la misa. Los demonios que la poseían alimentaban estas dudas, para que la joven monja no hiciera otra cosa que reírse y blasfemar abiertamente contra todas esas prácticas; pero su actitud confirmaba la suprema verdad del dogma católico.

\section{Conclusión}

A través de nuestra exposición nos concentramos en determinar cómo el caso de Jeanne Féry comprendió algo más que una posesión diabólica en estricto sentido. Es necesario adosarle los conceptos de misticismo y obsesión demoníaca para tener una imagen más acabada sobre el mismo. Así, es insoslayable comprender que éste fue un producto particular y especifico de una cultura que en términos más generales estaba siendo desgarrada por violentos conflictos entre los católicos y los reformados (Peña, 2011: 191-204). 


\section{Bibliografía}

\section{Fuentes primarias}

"Bourneville, D. M. (1886)., La Possession de Jeanne Féry, religieuse professe du couvent des sœurs noires de la ville de Mons (1584), Bibliothèque Diabolique, «Collection Bourneville». Paris.

\section{Fuentes secundarias}

"Dominguez, N. et al (eds.) (2011). Miradas y saberes de lo monstruoso. Buenos Aires: Editorial de la Facultad de Filosofía y Letras / Universidad de Buenos Aires.

»Ferber, S. (2004). Demonic Possession and Exorcism in Early Modern France. Londres: Routledge.

» Oberman H. A. (1994). The Reformation: Roots and Ramifications. Londres: T\&T Clark International.

"Pearl, J, L. (1999). The crimes of crimes: demonology and politics in France 15601620. Waterloo (Ontario): Wilfrid Laurier University Press.

»Peña, S. F. (2011). “¿Sueñan los demonios con adolescentes católicas? El 'milagro de Laon' de 1566: entre el pacto monstruoso y la polémica confesional”, en Domínguez, N. et al. (eds.), Miradas y saberes de lo monstruoso. Buenos Aires: Editorial de la Facultad de Filosofía y Letras, Universidad de Buenos Aires. 